\title{
The association between air pollution and the daily number of deaths: findings from the Slovak Republic contribution to the APHEA project
}

\author{
L Bachárová, K Fandáková, J Bratinka, M Budinská, J Bachár, M Gudába
}

\begin{abstract}
Study objective - To analyse the short term relation between daily air pollutant values and the daily number of deaths in Bratislava, Slovak Republic, during the study period 1987-91.

Design - This follows the APHEA protocol. The association between the daily number of total and cause specific deaths and daily variations in ambient air levels of sulphur dioxide $\left(\mathrm{SO}_{2}\right)$ and total suspended particulates (TSP) were analysed using Poisson regression that allowed control for meterological data and variables that handle temporal and autoregressive patterns.

Setting - Bratislava is the capital town of Slovakia, the total population was 442999 according to 1991 census data. The dominant sources of industrial air pollution are the chemical industry and oil refinery. Main results and conclusions - After adjustment for season, temperature and relative humidity, days of week and holidays, secular trends, and autoregressive patterns no significant associations were found between the daily variations in the air pollutants, $\mathrm{SO}_{2}-24 \mathrm{~h}$ and TSP-24 h, and total mortality (RR 0.978, 95\% CI 0.96 , 0.99; RR 1.008, 95\% CI 0.96, 0.99) and cause specific mortality in Bratislava during the study period.
\end{abstract}

( $($ Epidemiol Comm Health 1996;50(Suppl 1):S19-S21)

APHEA is an international multicentre project using an extensive database derived from 10 different European countries which represent various social, environmental, and air pollution situations. The aim is to provide quantitative estimates of the short term health effects of air pollution. ${ }^{1}$ The Slovak group joined APHEA in January 1994, one year after it had begun, under the Program of Cooperation in Science and Technology with Central and Eastern European Countries and with New Independent States of the former Soviet Union (PECO), which has enabled Slovakia to collaborate with partners from the European Community in an ongoing research project. This report presents the results of analyses of daily mortality and air pollution during the period 1987-91 in Bratislava, Slovak Republic.

\section{Methods}

STUDY PERIOD

For the purpose of this study the period 1987-91 was selected. In 1992, a new automated monitoring system was installed in Bratislava and in other monitoring stations, and different measurement methods were introduced. The study period covers a period of political and economic changes, which can be characterised briefly in terms of an increase in traffic, intermittent reduction of industrial production, and the introduction of new technologies.

\section{STUDY AREA}

Bratislava is the capital of Slovakia. It is situated on the river Danube, at the foot of the Small Karpathian Mountains, close to the Austrian and Hungarian borders, and approximately $150 \mathrm{~m}$ above sea level. Chemical industry and oil refinery are the dominant sources of industrial air pollution. The population data used in this study were drawn from 1991 mid-year census; the total population was 442999.

\section{MORTALITY INDICES}

The daily number of deaths classified according to ICD 9, and the place of residence of deceased subjects were provided by The Statistical Office of the Slovak Republic. The data were originally taken from death certificates. The mortality data were classified according to:

- Total daily number of deaths,

- Total daily number of deaths minus deaths from external causes (ICD $>=800$ ),

- Total daily number of deaths from respiratory causes (ICD 460-519),

- Total daily number of deaths respiratory infections (ICD 480-486, 466),

- Total daily number of deaths from obstructive lung diseases (ICD9 490-496),

- Total daily number of deaths from cardiovascular causes (ICD 390-459),

- Total daily number of deaths from ischemic heart diseases (ICD 410-414),

- Total daily number of deaths from lung cancer (ICD 162),

- Total daily number of deaths from diseases of the digestive system (ICD 520579 ). 
Table 1 Descriptive statistics of daily data on mortality in Bratislava for the study period 1987-91: Total mortality, deaths from respiratory diseases (ICD 460-519), deaths from cardiovascular causes (ICD 390-459), and deaths from diseases of the digestive system (ICD 520-579).

\begin{tabular}{lllll}
\hline $\begin{array}{l}\text { Mortality indices } \\
\text { (deaths/day) }\end{array}$ & Season* & Mean & $(S D)$ & (Range) \\
\hline Total mortality & 1 & $10 \cdot 96$ & $(3 \cdot 36)$ & $(3-21)$ \\
& 2 & $10 \cdot 47$ & $(3 \cdot 10)$ & $(3-22)$ \\
& 4 & $9 \cdot 95$ & $(3 \cdot 42)$ & $(2-21)$ \\
& $10 \cdot 38$ & $(3 \cdot 45)$ & $(3-22)$ \\
ICD 460-519 & 1 & $0 \cdot 70$ & $(0 \cdot 85)$ & $(0-4)$ \\
& 2 & $0 \cdot 69$ & $(0 \cdot 85)$ & $(0-4)$ \\
& 3 & $0 \cdot 68$ & $(0 \cdot 85)$ & $(0-5)$ \\
ICD 390-459 & 4 & $0 \cdot 63$ & $(0 \cdot 83)$ & $(0-5)$ \\
& 1 & $5 \cdot 72$ & $(2 \cdot 46)$ & $(1-18)$ \\
& 2 & $5 \cdot 15$ & $(2 \cdot 28)$ & $(0-12)$ \\
ICD 520-579 & 3 & $4 \cdot 91$ & $(2 \cdot 34)$ & $(0-4)$ \\
& 4 & $5 \cdot 18$ & $(2 \cdot 27)$ & $(0-12)$ \\
& 1 & $0 \cdot 55$ & $(0 \cdot 78)$ & $(0-4)$ \\
& 2 & $0 \cdot 57$ & $(0 \cdot 77)$ & $(0-4)$ \\
& 3 & $0 \cdot 51$ & $(0 \cdot 71)$ & $(0-3)$ \\
& 4 & 0.53 & $(0 \cdot 73)$ & $(0-4)$ \\
\hline
\end{tabular}

* $1=$ winter; 2 =spring; $3=$ summer; $4=$ autumn

Table 2 Descriptive statistics of daily data on air pollution and meteorology in Bratislava for the study period 1987-91

\begin{tabular}{llrrr}
\hline & Season & \multicolumn{1}{c}{ Mean } & \multicolumn{1}{c}{$(\mathrm{SD})$} & \multicolumn{1}{c}{ (Range) } \\
\hline $\mathrm{SO}_{2}-24 \mathrm{~h}$ & 1 & $42 \cdot 82$ & $(47 \cdot 56)$ & $(10-490)$ \\
$\left(\mu \mathrm{g} / \mathrm{m}^{3}\right)$ & 2 & $20 \cdot 14$ & $(18 \cdot 88)$ & $(10-180)$ \\
& 3 & $11 \cdot 86$ & $(4 \cdot 99)$ & $(10-90)$ \\
& 4 & $20 \cdot 32$ & $(16 \cdot 84)$ & $(10-160)$ \\
$\mathrm{TSP}-24 \mathrm{~h}$ & 1 & $101 \cdot 79$ & $(83 \cdot 06)$ & $(0-680)$ \\
$\left(\mu \mathrm{g} / \mathrm{m}^{3}\right)$ & 2 & $83 \cdot 98$ & $(56 \cdot 70)$ & $(10-720)$ \\
& 3 & $77 \cdot 84$ & $(56 \cdot 81)$ & $(10-590)$ \\
& 4 & $93 \cdot 86$ & $(69 \cdot 46)$ & $(10-690)$ \\
$24 \mathrm{~h}$ temperature & 1 & $0 \cdot 87$ & $(4 \cdot 77)$ & $(-16 \cdot 00-12 \cdot 20)$ \\
$\left({ }^{\circ} \mathrm{C}\right)$ & 2 & $10 \cdot 27$ & $(5 \cdot 50)$ & $(-9 \cdot 20-23 \cdot 00)$ \\
& 3 & $19 \cdot 97$ & $(3 \cdot 43)$ & $(11 \cdot 40-29 \cdot 20)$ \\
& 4 & $10 \cdot 01$ & $(6 \cdot 10)$ & $(-6 \cdot 10-22 \cdot 90)$ \\
$24 \mathrm{~h}$ relative humidity & 1 & $80 \cdot 95$ & $(9 \cdot 97)$ & $(45 \cdot 00-98 \cdot 00)$ \\
$(\%)$ & 2 & $68 \cdot 12$ & $(11 \cdot 07)$ & $(36 \cdot 00-94 \cdot 00)$ \\
& 3 & $65 \cdot 22$ & $(10 \cdot 25)$ & $(39 \cdot 00-90 \cdot 00)$ \\
& 4 & $77 \cdot 27$ & $(9 \cdot 07)$ & $(49 \cdot 00-97 \cdot 00)$ \\
\hline
\end{tabular}

AIR POLLUTION DATA

The daily mean concentrations of sulphur dioxide $\left(\mathrm{SO}_{2}-24 \mathrm{~h}\right)$ and of total suspended particles (TSP-24 h) were measured. For determination of the $\mathrm{SO}_{2}-24 \mathrm{~h}$ concentration in ambient air, an aspiration colorimetric method was used; for the determination of TSP-24 h a filtration gravimetric method was employed. Nine monitoring stations were operating during the period 1987-91 in Bratislava. Of these, two urban stations were located near roads with frequent traffic, four stations were located in the neighbourhood of chemical factories, and three were in suburban areas. For further analysis, four stations were selected fulfilling the following criteria: they had the highest concentration of measured pollutants and the percentage of missing data did not exceed $15 \%$ for the whole study period and $25 \%$ for each year.

METEROLOGIC DATA

The daily data for 24 hour average temperature and 24 hour average relative humidity were available from the regular meteorological database of the Slovak Hydrometerologic Institute.
MODELLING

Poisson regression was used for data analysis, the procedure for model building followed the general rules of the APHEA protocol. The complete model for daily counts of deaths included the following variables: (1) long term trends, (2) seasons, (3) days of week and holidays effect, (4) short term effect of meterological conditions - temperature and relative humidity, (5) short term effects of air pollutants $\mathrm{SO}_{2}-24 \mathrm{~h}$ and TSP-24h.

Long term trends were controlled for by introducing both linear and quadratic transformations for trend and a dummy variable per each year. Sinusoidal terms were introduced into the model up to the 6 th order to control for seasons. Six dummy variables were formed for the days of the week and for holidays to control for the day of the week effect. Linear and quadratic transformations of humidity and temperature of the current day values, and 1 day lag for transformed values of temperature and humidity were introduced. Air pollution variables were assessed with up to three days lag in the model. The best model was fitted for current daily values of $\mathrm{SO}_{2}-24 \mathrm{~h}$ and TSP-24 h (lag for 0,1 , and 2 days, and averages of consecutive lags were tested). Finally, Poisson regression models were fitted including up to the 3rd autoregressive parameters.

\section{Results}

The total number of deaths during the five year period was 19062 . Results of the descriptive statistics for mortality over the period 1987-91 are presented in table 1.

Relatively low levels of $\mathrm{SO}_{2}-24 \mathrm{~h}$ were observed during the study period. The mean daily concentrations measured in Bratislava exceeded the upper recommended limit according to the air quality guidelines for Slovakia $^{2}\left(150 \mu \mathrm{g} / \mathrm{m}^{3}\right)$ in $14 \%$ of cases. The mean daily TSP $-24 \mathrm{~h}$ values exceeded the upper recommended limit of $150 \mu \mathrm{g} / \mathrm{m}^{3}$ in $26 \%$ of cases. Results of the descriptive statistics for air pollution and meterological data, characterising the situation in Bratislava, are presented in table 2 .

The correlation coefficients between daily $\mathrm{SO}_{2}-24 \mathrm{~h}$ values measured at four stations on the same day were relatively high $(0.832,0.851$, and 0.762 ). Correlations were lower for TSP$24 \mathrm{~h}$ values from different stations $(0.340$, $0 \cdot 301$, and 470 ). Correlation coefficients between TSP-24 $\mathrm{h}$ and $\mathrm{SO}_{2}-24 \mathrm{~h}$ measured at the same stations were low, between 0.008 and $0 \cdot 230$.

The results of the final Poisson model for $\mathrm{SO}_{2}$ and TSP are presented in tables 3 and 4. After adjusting the data for long term trends, seasons, days of week and holidays, temperature, and relative humitidy, no effect of $\mathrm{SO}_{2}$ and TSP was apparent over the whole study period (table 5 ).

\section{Discussion}

Several explanations can be proposed for the lack of relation between the daily variations of 
Table 3 Results of the final Poisson model for total daily mortality for sulphur dioxide $\left(\mathrm{SO}_{2}\right)$

\begin{tabular}{|c|c|c|c|}
\hline Parameter & Estimate & $S E M$ & $(95 \% C I)$ \\
\hline Intercept & $2 \cdot 3332$ & $0 \cdot 2803$ & $(1 \cdot 7833,2.8831)$ \\
\hline $\mathrm{SO}_{2}$ & -0.0004 & 0.0005 & $(-0.0014,0.0005)$ \\
\hline L1 temp & -0.0062 & 0.0036 & $(-0.0133,0.0008)$ \\
\hline L1 temp2 & 0.0001 & 0.0003 & $(-0.0005,0.0008)$ \\
\hline L1temp3 & 0.0000 & 0.0000 & $(-0.0000,0.0000)$ \\
\hline Llhum & -0.0017 & 0.0076 & $(-0.0167,0.0131)$ \\
\hline L1hum2 & 0.0000 & 0.0000 & $(-0.0000,0.0001)$ \\
\hline Year 88 & 0.0133 & 0.0276 & $(-0.0409,0.0675)$ \\
\hline Year 89 & $0 \cdot 0481$ & 0.0270 & $(-0.0050,0.1012)$ \\
\hline Year 90 & 0.0550 & 0.0284 & $(0.0008,0.1108)$ \\
\hline Year 91 & 0.0706 & 0.0280 & $(0.0156,0.1257)$ \\
\hline Tuesday & -0.0399 & 0.0309 & $(-0.1006,0.0208)$ \\
\hline Wednesday & -0.0289 & 0.0309 & $(-0.0895,0.0317)$ \\
\hline Thursday & -0.0325 & 0.0306 & $(-0.0925,0.0275)$ \\
\hline Friday & 0.0056 & 0.0303 & $(-0.0537,0.0651)$ \\
\hline Saturday & -0.0498 & 0.0308 & $(-0.1103,0.0105)$ \\
\hline Sunday & -0.0761 & 0.0310 & $(-0.1370,-0.0153)$ \\
\hline Cos 1 & 0.0834 & $0 \cdot 0283$ & $(0.0277,0.1391)$ \\
\hline Sin 1 & 0.0410 & 0.0144 & $(0.0127,0.0694)$ \\
\hline $\operatorname{Cos} 2$ & -0.0188 & 0.0136 & $(-0.0456,0.0080)$ \\
\hline $\operatorname{Sin} 2$ & -0.0384 & 0.0131 & $(-0.0642,-0.0125)$ \\
\hline Autoregression 1 & -0.0042 & 0.0255 & $(-0.0542,0.0458)$ \\
\hline Autoregression 2 & -0.0379 & 0.0254 & $(-0.0879,0.0120)$ \\
\hline Autoregression 3 & -0.0511 & $0 \cdot 0254$ & $(-0.1010,-0.0011)$ \\
\hline
\end{tabular}

Table 4 Results of the final Poisson model for total daily mortality for total suspended (TSP)

\begin{tabular}{|c|c|c|c|}
\hline Parameter & Estimate & SEM & $(95 \% C I)$ \\
\hline Intercept & $2 \cdot 6134$ & 0.3334 & $(1.9590,3 \cdot 2678)$ \\
\hline TSP & 0.0000 & 0.0002 & $(-0.0004,0.0004)$ \\
\hline Ll temp & -0.0043 & 0.0042 & $(-0.0127,0.0041)$ \\
\hline L1 temp2 & 0.0006 & 0.0005 & $(-0.0004,0.0016)$ \\
\hline L1 temp3 & -0.0000 & 0.0000 & $(-0.0000,0.0000)$ \\
\hline L1hum & -0.0116 & 0.0090 & $(-0.0294,0.0061)$ \\
\hline L1hum2 & 0.0000 & $0 \cdot 0000$ & $(-0.0000,0.0001)$ \\
\hline Year 88 & 0.0342 & 0.0310 & $(-0.0266,0.0950)$ \\
\hline Year 89 & $0 \cdot 0780$ & 0.0307 & $(0.0176,0.1384)$ \\
\hline Year 90 & 0.0799 & 0.0343 & $(0.0125,0.1474)$ \\
\hline Year 91 & 0.0633 & 0.0432 & $(0.0215,0.1483)$ \\
\hline Tuesday & -0.0198 & 0.0399 & $(-0.0982,0.0585)$ \\
\hline Wednesday & -0.0115 & 0.0390 & $(-0.0881,0.0651)$ \\
\hline Thursday & 0.0005 & 0.0394 & $(-0.0768,0.0779)$ \\
\hline Friday & 0.0615 & 0.0382 & $(-0.0134,0.1365)$ \\
\hline Saturday & -0.0125 & 0.0385 & $(-0.0882,0.0631)$ \\
\hline Sunday & -0.0354 & 0.0386 & $(-0.1113,0.0404)$ \\
\hline Cos 1 & 0.0874 & 0.0379 & $(0.01304,0.1618)$ \\
\hline $\operatorname{Sin} 1$ & 0.0221 & $0 \cdot 0184$ & $(-0.0140,0.0584)$ \\
\hline $\operatorname{Cos} 2$ & -0.0334 & 0.0174 & $(-0.0449,0.0236)$ \\
\hline $\operatorname{Sin} 2$ & -0.0106 & 0.0164 & $(-0.0657,-0.0011)$ \\
\hline Autoregression 1 & -0.0066 & 0.0317 & $(-0.0688,0.0556)$ \\
\hline Autoregression 2 & -0.0315 & 0.0312 & $(-0.0928,0.0298)$ \\
\hline
\end{tabular}

Table 5 Relative risks (RR) and 95\% confidence intervals for total mortality, deaths from cardiovascular causes (ICD 390-459), and deaths from diseases of the digestive system (ICD 520-579) in relation to sulphur dioxide $\left(\mathrm{SO}_{2}\right)$ and total suspended particulates $(T S P)$

\begin{tabular}{|c|c|c|c|c|}
\hline & \multicolumn{2}{|c|}{$\mathrm{SO}_{2}-24 h$} & \multicolumn{2}{|c|}{$T S P-24 h$} \\
\hline & $R R$ & $(95 \% C I)$ & $R R$ & $(95 \% C I)$ \\
\hline $\begin{array}{l}\text { Total mortality } \\
\text { ICD 390-459 } \\
\text { ICD 520-579 }\end{array}$ & $\begin{array}{l}0.978 \\
0.986 \\
1.035\end{array}$ & $\begin{array}{l}(0.96,0.99) \\
(0.94,1.00) \\
(1.01,1.05)\end{array}$ & $\begin{array}{l}1.008 \\
0.989 \\
0.999\end{array}$ & $\begin{array}{l}(0.96,0.99) \\
(0.93,1.02) \\
(0.95,1.01)\end{array}$ \\
\hline
\end{tabular}

air pollutants, $\mathrm{SO}_{2}$ and TSP, and total and cause specific mortality in Bratislava during the study period 1987-91. Firstly, the relatively small number of inhabitants in Bratislava, resulted in small numbers of deaths per day. There are two main objections to this explanation. In comparable or even smaller towns significant associations were found. ${ }^{34}$ Mortality as a rare event can be modelled by Poisson regression.

The second explanation may lie in the availability of data. Before the installation of the automated monitoring system in 1991, limited data on air pollution were available - only the mean daily concentration of $\mathrm{SO}_{2}$ and TSP. These data might not express sufficiently the air pollution in the town.

The last explanation concerns effect modifiers. International comparison showed that a newborn boy in the Slovak Republic had an average life expectancy in 1990 of 66.6 years, in contrast to 72 years for his neighbour in Austria, 73 years in United Kingdom, and 79 years in Japan. Less pronounced is the difference in female life expectancy: 75.4 years in the Slovak Republic versus 78 years in Austria and 78.5 years in the United Kingdom. The most important causes of death according to potential years of life lost are cardiovascular diseases and cancer. The likely contributors to these differences, for example newborn mortality or prevalence of smoking and smoking related diseases, are comparable in the Slovak Republic to those in other countries. The newborn mortality was 11.2 in 1990 . The prevalence of smoking in the Slovak Republic during the period $1981-89$ was $44.8 \%$ in the male population aged $30-59$ years and $11.9 \%$ for the female population. The incidence of lung cancer in 1990 was $11 \cdot 3 / 1000000$ for females (compared with the European standard of 11.31 ) and 83.15 for males (European standard $108 \cdot 87) .^{56}$

In the 1960s, the mortality in Slovakia (in former Czechoslovakia) was comparable to that in other developed European countries. Negative trends in mortality and rates of noncommunicable diseases started in the 70s, and in contrast to most west European countries the trends are still negative. It is not fully understood why this situation has developed and more detailed studies are therefore being carried out.

1 Katsouyanni K, Zmirou D, Spix C, et al. Short-term effects of air pollution on health: A European approach using ground objectives, design. Eur Respir 7 , 1995;8:1030-38. 2 Air quality guidelines for Slovak Republic. Bratislava: Ministry of Health of Slovak Republic, 1991 .

Ge Touloumi G, Balducci F, Spix C, et al. The APHEA project: Results I: Total mortality. Epidemiology 1995;6:S40.

4 Spix C, Heinrich J, Dockery D, et al. Air pollution and daily mortality in Erfurt, East Germany, 1980-1989. Environ Health Prospect, 1993;101: 518-26.

5 Rusnák, Egnerová $\mathrm{H}$, Fandáková K. The implications of inequalities in health status for the health policy priorities in the Slovak Republic. In: Noncommunicable disease prevention: Office for Europe, 1994; 65-72.

6 HFA indicators and monitoring. The European region. Slovak Republic . National Centre for Health Promotion, 1994. 